\title{
Effectiveness of a Simulation-based Empathy Enhancement program for the Carer of the elderly (SEE-C)
}

\author{
Tae Hui Kim,M.D. ${ }^{1}$, Areum Han, PhD. ${ }^{2}$
}

1. Department of Psychiatry, Wonju Severance Christian Hospital, Yonsei University, Wonju College of Medicine, Wonju, Korea

2. Department of Occupational Therapy, Yonsei University, Wonju, Korea

\section{Introduction}

Empathy has been described as an essential competence of healthcare professionals who are working in the care of elderly'. It is related to the quality of caring and it strengthens the motivation of caregivers.

\section{Objectives}

This study aimed to develop a simulation based empathy program for elderly caregivers and to evaluate the effects of the improvement of empathy and reducing the empathy burnout.

\section{Method}

Based on the Dementia Live ${ }^{\mathrm{TM}}$ program developed by the AGEu-cate Training Institute for the Elderly in the United States ${ }^{2}$, the author's permission was granted for the purpose of research, the program for the elderly empathy enhancement program was modified to suit the Korean situation ${ }^{3}$. After that, we developed Simulation-based Empathy Enhancement program for the Carer of the elderly (SEE-C) by combining mindfulness. It was conducted to social workers and hiring caregivers who care for the elderly in the community. The Korean version of the empathy quotient short form (EQ-Short-K), Korean version of the Jefferson sympathy scale for health professionals(K-JES-HP), and Korean Version of Professional Quality of Life Scale 5(KProQOL 5) were administered before and after SEE-C. Paired ttest and/or Wilcoxon signed rank test were performed.

\section{Results}

A total of 104 , each 52 social workers and hiring caregivers participated in the study. The average age of the social worker was $39.62 \pm 10.16$, and the caregiver was $52.10 \pm 6.43$. There were significant improvements in K-JES-HP, especially, perspective taking and standing in the patient's shoe in social workers. Also there were significant improvements in K-ProQOK 5 by reducing in compassion fatigue composed of secondary traumatic stress and burnout in social workers. But there was no significant difference in the hiring caregiver(Table 1).

\section{Discussion}

These finding suggested that SEE-C is effective in promoting empathy and reducing fatigue of social workers who are caring for the elderly. Although the hiring caregivers who visited the home of the elderly to assist their daily life could not confirm the effectiveness of the program, it could be considered the need for differentiation of the empathy enhancing program according to the health care role for the elderly.

\section{Reference}

1. Kelm, Z., Womer, J., Walter, J. K., \& Feudtner, C. Interventions to cultivate physician empathy: A systematic review. BMC Medical Education, 2014 Oct 14;14 219. doi:10.1186/1472-6920-14-219

2. https://ageucate.com/index.php

3. Han A, Kim TH, \& Hong H . Experiences of caregivers of people with dementia in a Korean dementia simulation program. Dementia(London), 2019 Jan 9:1471301218823453. doi: 10.1177/1471301218823453.

Table 1. Pre-post program differences by subjects

\begin{tabular}{|c|c|c|c|c|c|c|}
\hline & \multicolumn{3}{|c|}{ Social workers $(n=52)$} & \multicolumn{3}{|c|}{ Hiring caregivers $(n=52)$} \\
\hline & Pre & Post & $\mathrm{p}$-value & Pre & Post & $\mathrm{p}$-value \\
\hline EQ-Short-K & $10.75 \pm 3.85$ & $10.46 \pm 3.66$ & 0.944 & $10.04 \pm 2.44$ & $10.85 \pm 3.49$ & 0.125 \\
\hline K-JES-HP & $104.79 \pm 11.08$ & $107.58 \pm 11.91$ & 0.003 & $104.94 \pm 9.04$ & $104.83 \pm 10.74$ & 0.895 \\
\hline perspective taking & $57.60 \pm 5.68$ & $59.02 \pm 6.34$ & 0.008 & $58.96 \pm 5.04$ & $58.27 \pm 5.60$ & 0.359 \\
\hline compassionate care & $36.98 \pm 5.09$ & $37.75 \pm 5.02$ & 0.089 & $34.88 \pm 5.38$ & $35.50 \pm 5.22$ & 0.214 \\
\hline standing in the patient's shoe & $7.85 \pm 2.44$ & $8.98 \pm 2.83$ & 0.002 & $8.09 \pm 2.39$ & $9.23 \pm 2.51$ & 0.424 \\
\hline \multicolumn{7}{|l|}{ K-ProQOL 5} \\
\hline compassion satisfaction & $39.46 \pm 5.43$ & $39.31 \pm 5.29$ & 0.894 & $39.10 \pm 4.09$ & $39.12 \pm 4.57$ & 0.965 \\
\hline $\begin{array}{l}\text { compassion fatigue } \\
\text { (secondary traumatic stress ) }\end{array}$ & $26.38 \pm 4.77$ & $24.94 \pm 5.05$ & 0.006 & $27.62 \pm 4.38$ & $27.25 \pm 5.04$ & 0.535 \\
\hline compassion fatigue (burnout) & $24.08 \pm 4.68$ & $22.87 \pm 4.78$ & 0.024 & $23.88 \pm 4.11$ & $23.48 \pm 4.05$ & 0.751 \\
\hline
\end{tabular}

EQ-Short-K: The Korean version of the empathy quotient short form, K-JES-HP: Korean version of the Jefferson sympathy scale for health professionals, K-ProQOL 5: Korean Version of Professional Quality of Life Scale 5 